\title{
An investigative study on the effects of mechanical parameters of an automated grain drinks processing machine on drink consistency
}

\author{
${ }^{1 *}$ Gana, I.M., ${ }^{2}$ Gbabo, A., ${ }^{1}$ Shehu, A.A., ${ }^{1}$ Mohammed, K.M., ${ }^{2}$ Dauda, S.M. and \\ ${ }^{3}$ Ahmad, D. \\ ${ }^{I}$ Department of Agricultural and Bioenvironmental Engineering, School of Engineering, Federal \\ Polytechnic Bida, P.M.B. 55, Niger State Nigeria \\ ${ }^{2}$ Department of Agricultural and Bioresources Engineering, School of Engineering, Federal University of \\ Technology Minna, P.M.B. 65, Niger State Nigeria \\ ${ }^{3}$ Department of Biological and Agricultural Engineering, Faculty of Engineering, Universiti Putra \\ Malaysia, 43400 UPM Serdang, Selangor Darul Ehsan, Malaysia
}

\begin{abstract}
Article history:
July 2018

November 2018

Keywords:

Automated,

Consistency,

Drink,

Grain,

Mechanical
\end{abstract}

Received: 20 May 2018

Received in revised form: 19

Accepted: 20 July 2018

Available Online: 6

\section{DOI:}

https://doi.org/10.26656/fr.2017.2(6).112

\begin{abstract}
A response surface methodology (RSM) has been utilized for investigating the dynamics of mechanical parameters of a developed automated grain drinks processing machine. Also, the optimal values capable of yielding low and high drink consistency were established. The machine integrates the blending of soaked grains, mixing of the slurry, extraction of the aqueous liquid and discharging of paste out of the machine all together in a single unit. Its mechanical parameters, which include blade type, basket orientation, and speed, have been investigated while drink consistency was used as performance characteristics. The experiment was based on a central composite rotatable design (CCRD). The result of the experimental revealed that the highest consistency of 7.67 was obtained from an interaction between 3 blades assembly, basket with half angle of $30^{\circ}$ and speed of $1400 \mathrm{rpm}$, while the least consistency of 1.96 was obtained from an interaction between 4 blades assembly, basket with half angle of $40^{\circ}$ and speed of $864 \mathrm{rpm}$. Numerical optimization carried out with the goal of maximizing the consistency revealed optimum values of 3-blade assembly, basket orientation of $46.89^{\circ}$ and speed of $1400 \mathrm{rpm}$ for consistency of 7.68 with a desirability of 0.999 . But when the goal was to minimize the consistency the optimum values of 5-blade assembly, basket orientation of $50^{\circ}$ and speed of $1000 \mathrm{rpm}$ were obtained, while the milk consistency and desirability were 2.57 and 0.894 , respectively. The blade type and the speed of rotation were the most influential variables affecting the drink consistency. The result of this study provided standard input machine variables capable of yielding soya milk with various consistencies to meet the consumer's desire.
\end{abstract}

\section{Introduction}

Grain drinks are nutritious food product produced from processing of legumes and cereals grains such as soya beans and sorghum among others. It has numerous social economic and health benefits. According to Aminat et al. (2013), grain beverages are highly nutritious and their production cost is low compared to that of soft drinks. Gbabo et al. (2012), reported grain beverages to include kunu (Hausa) a non-alcoholic beverage made from maize, millet, sorghum and groundnut, grain milk and soya milk. Soya milk is the final product obtained from blending soaked soya beans, mixing the slurry with water and extracting the aqueous milk (Gana et al., 2017). Its major constituents include water, fat carbohydrate, protein, and vitamins. The level of its water content can be modified in order to obtain products with different consistencies, such as soya milk, soya milk drink, and concentrated soya milk. Soya Foods Association of America (SRAA) (1996), reported on the nutritional value of different soya product as follows; soya milk to contain about $3 \%, 1 \%$ and $7 \%$, protein, fat and total solid respectively and 1.5 to $2.9 \%, 0.5 \%$, and $3.9 \%$ respectively in soya drink. Also, $6 \%$ protein, $2 \%$ soybean oil and $14 \%$ total solid for soya milk concentrate. The increase awareness of the high nutritional content of soya milk coupled with its health 
benefits and quest for low-cost source of protein has led to its household small-scale production. The disadvantage of this method is that the production is carried out with little or no adherence to standard procedure, hygiene and quality control measures (Odu et al., 2012; Gana et al., 2017). The nutritional content and consistency of most grain beverages vary depending on the variety of grain and processing method employed (Onuorah, 2007). The equipment used also influenced the composition of water in the product, which in turns determines the thickness or consistency of the final product. Manufacturers, at all levels, tried to improve the quality of products so as to meet consumer's demand. According to Odu et al. (2012), among the steps taking by soya milk manufacturers to ensure acceptability of their product is improving on the sensory quality of the milk especially the flavor, taste, and consistency. Also, Terhaag et al. (2013), observed that some soya milk manufacturer's best meets consumer expectations of their plain soya milk beverage by increasing the viscosity, protein content, consistency and darken the colour of the milk. Therefore, consistency level of soybased beverages is one of the major factors that influence the consumer's acceptance and preference of the product. At all time, the major target of processors is to have a maximum output of a product and at the same time, the product should be capable of yielding profit on commercial scale. Hence, the major factors here are the maximum output and the production method that is capable of producing a hygienic product with good quality and market acceptability. These factors are not addressed by the traditional household method of soya milk production in Nigeria. This could be as results of the following; the type of wet milling machines and equipment (made from mild steel materials) used in the production process. The use of non-standard method involving different stages and different equipment that produced a product with varying moisture content and consistency from one processor to another (Gana et al., 2017). To address these shortcomings an automated grain drink processing machine that integrates blending of soaked grains, mixing the slurry with water, extraction of the aqueous liquid and expelling of paste out of the machine together and finished in a single unit was developed (Gana et al., 2017). Currently, the manufacturers of various products use precision, standard method and the minimum time to produced quality product. This has given rise to a situation which requires the knowledge of optimum values of various input parameters to maximize or minimise a particular output (Shashikant et al., 2014). Therefore, the objective of this study is to investigate the effects of mechanical parameters such as blade configuration, basket orientation and combine the speed of rotation of the blade and a centrifugal basket of an automated grain drink processing machine on the drink consistency. Also to established optimum parameters of the machine capable of yielding the drink with low and high consistencies.

\section{Materials and methods}

\subsection{Soya bean samples preparation}

Twenty kilogrammes of soya beans of TGX 1954IFXTGX 1835-10E variety was sourced from Minna central Market Niger State Nigeria. It was sorted, cleaned and washed with tap water to remove foreign materials before dividing into twenty samples of $1 \mathrm{~kg}$ each. Each of the samples was soaked separately in water for $12 \mathrm{hrs}$ at room temperature of $28^{\circ} \mathrm{C}$ as recommended by Gaffa et al. (2003). The soaked soybean's husk was removed by means of the pressure of two hands and cleaned with continuous flow of fresh water. Then the clean dehulled samples were processed using the grain processing machine based on the design matrix shown in Table 1.

\subsection{Equipment}

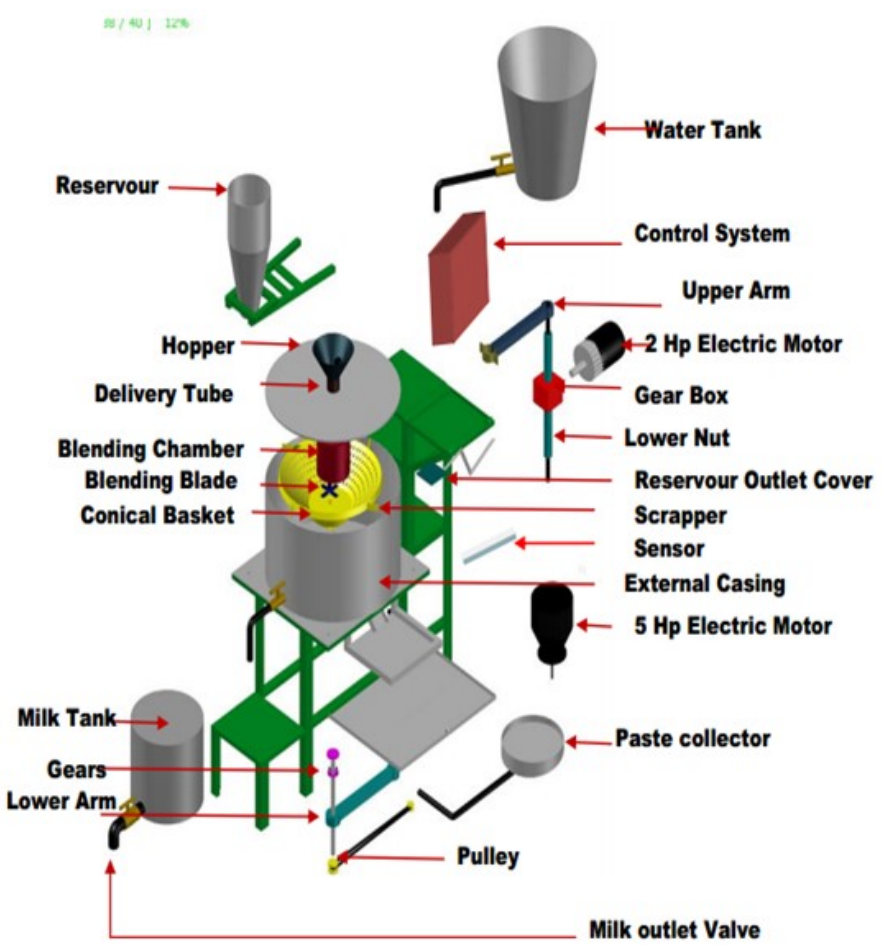

Figure 1. Exploded View of the Automated Grain Drinks Processing Machine (Gana et al., 2017)

An automated grain drink processing machine (Figure 1) developed by Gana et al. (2017) was used in this study. The machine integrates blending of soaked grains, mixing the slurry with water, extraction of the aqueous liquid and expelling of paste out of the machine together and finished at a go. The major components of the machine are as follows; outer casing, conical centrifugal basket, internal casing, hopper, delivery pipe, 
Table 1. Matrix transformation of five level- three factors central composite rotatable design of the experiment

\begin{tabular}{cccccc}
\hline $\begin{array}{c}\text { Run } \\
\text { Ord }\end{array}$ & $\begin{array}{c}\text { Blade Config. } \\
\text { (No.) }\end{array}$ & $\begin{array}{c}\text { Basket Orien. } \\
\text { (Degree) }\end{array}$ & $\begin{array}{c}\text { Speed of Rotation } \\
\text { (rpm) }\end{array}$ & $\begin{array}{c}\text { Experimental } \\
\text { Consistency (Litres) }\end{array}$ & $\begin{array}{c}\text { Predicted Consistency } \\
\text { (Litres) }\end{array}$ \\
\hline 1 & 3 & 30 & 1000 & 6.7 & 6.65 \\
2 & 5 & 30 & 1000 & 6.16 & 6.31 \\
3 & 3 & 50 & 1000 & 7.67 & 7.46 \\
4 & 5 & 50 & 1000 & 6.78 & 6.31 \\
5 & 3 & 30 & 1400 & 6.55 & 6.12 \\
6 & 5 & 30 & 1400 & 6.8 & 6.99 \\
7 & 3 & 50 & 1400 & 7.67 & 7.74 \\
8 & 5 & 50 & 1400 & 1.96 & 1.97 \\
9 & 2 & 40 & 1200 & 3.76 & 3.54 \\
10 & 6 & 40 & 1200 & 4.75 & 5.03 \\
11 & 4 & 23 & 1200 & 6.78 & 6.79 \\
12 & 4 & 57 & 1200 & 3.97 & 4.17 \\
13 & 4 & 40 & 864 & 6.3 & 6.31 \\
14 & 4 & 40 & 1536 & 5.8 & 6.06 \\
15 & 4 & 40 & 1200 & 2.5 & 2.57 \\
16 & 4 & 40 & 1200 & 6.25 & 6.31 \\
17 & 4 & 40 & 1200 & 6.09 & 6.21 \\
18 & 4 & 40 & 1200 & 6.22 & 6.31 \\
19 & 4 & 40 & 1200 & 4.7 & 4.43 \\
20 & 4 & 40 & 1200 & 6.2 & 6.31 \\
\hline
\end{tabular}

blending chamber, blending blades assembly, gearbox, control system and electric motors. The outer casing is cylindrical in shape and is made up of stainless steel sheet. A liquid outlet valve was fitted to its bottom side in order to allow outflow of extracted aqueous liquid from the tank. A paste outlet chute was also fitted at the bottom of the casing for discharging of expelled paste. The conical centrifugal basket was fixed inside the machine casing. It has a lower impervious part to allow thorough washing of the milk from the paste and a smooth upper part with perforated openings to allow fluid drainage. A scraper was attached to the conical basket at the top from outside. It scrapes, conveys and discharges the expelled paste from the basket through the discharge outlet. The internal casing was attached to the internal wall of the outer casing. It is cylindrical in shape with its upper side opened in order to allow collection of expelled paste. The hopper serves as the reservoir where the grains are fed to the machine. It is made up of stainless steel sheet, and of conical shape. The delivery pipe is cylindrical in shape and conveys the grains directly to the blending chamber. The blending chamber is where the blending operation takes place. It was designed to prevent the materials from spilling and moving out of the chamber until after the blending operation is completed. The blending blades are interchangeable blades consisting of $2,3,4,5$ and 6 blades assembly with one of the blades used at a time. It is attached to the shaft inside the conical basket. The gearbox controls the movement of the upper and lower arms. It is responsible for the opening and the closing of the blending chamber, engagement, and disengagement of the basket from rotation. Programmable timer was used as the control system and was designed in such a way that the operating time can easily be varied. The control system consists of the following units; power and pre-set units, erasable programmable read-only memory, a display unit, and the relay unit. The electric motors used by the machine are $2 \mathrm{hp}$ and $5 \mathrm{hp}$ electric motors. The $2 \mathrm{hp}$ powered the gearbox while the $5 \mathrm{hp}$ powered the central shaft and the centrifugal basket (Gana, 2016; Gana et al., 2017).

\subsection{Experimental setup and plan}

A Response Surface Methodology was employed in this study using central composite rotatable design (CCRD). It consists of three factors which were varied at five levels (Anuonye, 2006). The CCRD consists of 20 experimental runs $\left(2^{\mathrm{k}}+2 \mathrm{k}+\mathrm{m}\right.$, where $\mathrm{k}$ is the number of factors and $m$ the number of replicated centre points), comprises of eight factorial point $\left(2^{\mathrm{k}}\right)$, six axial points $(2 \mathrm{k})$, and six replicated centre point $(\mathrm{m}=6)$. The $\mathrm{k}$ is the number of independent variables and the axial point have $\alpha=1.68$. Results from previous research (Gbabo et al., 2012; Gana, 2016) were used to establish a centre point of the CCRD for each factor. The three factors (machine functional parameters) are blending blade, centrifugal basket orientation and combine the speed of blending blade and basket rotation. The blending blade cuts the soya beans and reduced it to smaller sizes. It was varied at configurations of 2, 3, 4, 5 and 6-blades assembly. The centrifugal basket influenced the expelling of paste out of the machine and was varied as $23^{\circ}, 30^{\circ}, 40^{\circ}, 50^{\circ}$ and 
$57^{\circ}$ half angle. The other variable used is the combined speed of blending and basket rotation which influenced both the speed of rotation of the blade and the centrifugal basket. It was varied as 864, 1000, 1200, 1400 and 1536 rpm. The experiment was conducted base on the design matrix shown in Table 1. The machine functional parameters were the independent variables while the milk consistency was the dependent variable (response).

\subsection{Experimental procedure}

The component parts of the machine were assembled as reported by Gana et al. (2017). The control system of the machine was set at 5 mins blending time and 2 mins sieving time. The $5 \mathrm{hp}$ electric motor was switched on, the soaked grains were then fed into the machine through the hopper and immediately the blending operation commenced. This operation was displayed on the control system screen as machine status 'halt'. The operation continued until the inputted blending time elapsed and immediately the $2 \mathrm{hp}$ electric motor is reactivated and is rotated in a clockwise direction. Thereby, lifting the upper arm, this in turn also lifted the hopper assembly from the base of the basket. At the same time, the lower arm lifted the central shaft up until the gear attached to it meshed with that attached to the basket, thereby, engaging the basket in rotation with the central shaft for aqueous liquid extraction and expelling of paste from the basket. This action of upward movement of the lower and upper arms was displayed on the control system screen as machine status 'up' and extraction operation is displayed as machine status: halt. Due to the centrifugal force of $70.2 \mathrm{KN}$ generated by rotation of the basket and central shaft, the fluid migrated up along the basket wall (Gana, 2016). The aqueous liquid was separated from the paste by draining through the pore spaces between the granular material and the perforation on the basket. It was collected at the bottom of the external casing and flowed out of the machine through the filtrate outlet. The paste was expelled out of the basket at the end of the basket wall and collected at the internal screen where it was scrapped, conveyed and discharged out of the machine through the paste outlet by the scrapper. The next phase of the operation commenced following the same sequence.

\subsection{Determination of the drink consistency}

The consistency of a drink is an index of its concentration and thickness or the ability of the drink to retain its solid content. It was determined by comparing the total solid content of the raw soya milk samples with the standard value reported by SFAA (1996) and Gana (2016).

\subsection{Statistical analysis}

Design expert software package (version 7.0.0) was used for the regression and graphical analysis. A quadratic polynomial equation was developed to predict the response as a function of independent variables and their interaction. In general, the response for the quadratic polynomials is described below as reported by Aworanti et al. (2017):

$$
Y=\beta_{0}+\sum_{g=1}^{N} \beta_{g} x_{g}+\sum_{g=1}^{N} \beta_{g g} x_{g}^{2}+\sum_{g<f} \sum \beta_{g f} x_{g} x_{f}
$$

Where $\mathrm{Y}$ is the response (soya milk consistency), $\beta_{0}$ is the intercept coefficient, $\beta_{g}$ is the linear terms, $\beta_{g g}$ is the squared terms, $\beta_{g f}$ is the interaction terms, $x_{g}$ and $x_{f}$ are the uncoded independent variables.

Analysis of variance (ANOVA) was carried out to estimate the effects of main variables and their potential interaction effects on the soya milk consistency.

\subsection{Optimisation analysis}

Optimisation is the process of finding the best solution for a system or operation. The main purpose of optimisation is to achieve optimum conditions for the operation of a system or machine (Anuonye, 2006). In this study, the optimisation analysis of the independent variables and the dependent variables were carried out using the numerical technique in Design expert software.

\section{Results and discussion}

The effects of independent variables; blade configuration, basket orientation and speed on the drink consistency are presented in Table 1 . The consistency ranged from $1.96 \%$ to $7.67 \%$. The highest value of $7.67 \%$ was obtained from a combination of 3-blade assembly, basket with half angle of $30^{\circ}$ and speed of $1400 \mathrm{rpm}$, while the least consistency of $1.96 \%$ was obtained from an interaction between 4-blade assembly, basket with half angle of $40^{\circ}$ (angle of $50^{\circ}$ from the horizontal) and speed of $864 \mathrm{rpm}$.

The result of the statistical analysis of variance (ANOVA) of the experiment showed that the model terms were significant. The significant model terms were identified at $95 \%$ significance level. The Quadratic regression model equation developed to predict the soya milk consistency with respect to functional machine parameters (independent variables) is shown in equation 2. The model $\mathrm{F}$ - the value of 59.19 implies that the model is significant. There was only $0.01 \%$ chance that a Model $\mathrm{F}$ value this large could occur due to noise. The value of Probability $>\mathrm{F}$ less than 0.0500 indicated that model terms were significant. In this case, $\mathrm{A}, \mathrm{C}, \mathrm{A}^{2}$, and $\mathrm{C}^{2}$ were significant model terms. It can be clearly observed that $\mathrm{C}$ (speed) had more significant effect on 
machine output with a coefficient of an estimate of 1.49 .

The "Lack of Fit F-value" of 2.28 implies that the Lack of Fit is not significant relative to the pure error. There is a $19.38 \%$ chance that a "Lack of Fit F-value" this large value could occur due to noise. Non-significant lack of fit is good (Aworanti et al., 2007). The coefficient of variation (C.V) of $5.21 \%$ obtained was low which indicated that the deviation between experimental and predicted values were low as reported by Maran and Manikandam (2012). The coefficient of determination R value of 0.9908 indicated that the model was able to predict $99.08 \%$ of the variance and only $0.92 \%$ of the total variance was not explained by the model. The coefficient of correlation R- Squared value of 0.9816 was high very close to 1 as recommended by Xin and Saka (2008). Predicted R - Squared of 0.9872 was in reasonable agreement with the Adjusted $\mathrm{R}$ - Squared of 0.9650 which indicated that the experimental data fitted better. Adequate Precision of 27.58 is above the desired minimum value of 4 reported by Salam et al. (2014). This indicated that the model can be used to navigate the design space. The regressed milk consistency model equation is given as

$\mathrm{Y}_{\mathrm{C}}=6.31-0.78 A-0.17 B+1.49 C-0.94 A B+0.061 A C+0.22 B C-0.29 \mathrm{~A}^{2}-0.015 B^{2}-0.65 C^{2}$

Where, $\mathrm{Y}_{\mathrm{C}}$ is consistency of milk, $\mathrm{A}$ is Blade type (No), $\mathrm{B}$ is Basket orientation (Degree) and $\mathrm{C}$ is Speed of blending (rpm)

The model equation was improved by removing insignificant model terms. $\mathrm{P}$ - Values greater than 0.1000 implies that the model terms $\left(\mathrm{B}, \mathrm{AB}, \mathrm{AC}, \mathrm{BC}, \mathrm{ABC}, \mathrm{B}^{2}\right.$, $\mathrm{A}^{2} \mathrm{~B}, \mathrm{~A}^{2} \mathrm{C}, \mathrm{AB}^{2}, \mathrm{AC}^{2}, \mathrm{~B}^{2} \mathrm{C}, \mathrm{BC}^{2}, \mathrm{~A}^{3}, \mathrm{~B}^{3}$, and $\mathrm{C}^{3}$ ) were not significant. Consequently, the model was reduced to Equation 2 (Aworanti et al., 2017).

The fitted milk consistency model equation is given as:

$\mathrm{Y}_{\mathrm{C}}=6.31-0.78 A+1.49 C-0.29 \mathrm{~A}^{2}-0.65 \mathrm{C}^{2}$

It is obvious that variable $C$ (speed) in the model has positive co-efficient implying a direct proportionality while A (blade type) has negative coefficient implying an indirect proportionality. That is an independent increase in $\mathrm{C}$ increased the consistency of the raw soya milk. While the independent increase in A decreased the consistency of the raw soya milk. The model equation obtained was simulated and the consistency was observed to be within the experimental range. The actual values of consistency were found to be in close agreement with the predicted values.

\subsection{Response surface and contour plot for milk consistency}

The response surface and contour plot for milk consistency are presented in Figures 2 (a) and (b) respectively. The consistency was observed to increase from 5 to 7.6 with increased in speed of blending from $1000 \mathrm{rpm}$ to $1400 \mathrm{rpm}$. This could be due to more shearing and cutting action of the blades with an increase in the speed of blending. This conforms to result of an earlier study by Jayesh (2013) where high speed of blending resulted in more segregation of particles thereby increasing the solid content of the liquid. Also, consistency of the drink decreased from 5 to 3 with an increase in blade number from 3 to 5 blades assembly. This could be a result of decreased in cutting and shearing action of the blades with increased in number as all the blade were designed to have the same total area of cutting surfaces. Therefore, the length of the blades decreased with increase in number while it increased with a decrease in a number of the blades. This agreed with the result of an earlier study by Gbabo et al. (2012), where blade design was found to affect the total solid content of drinks produced from grains drink processing machine. Blade design with more contact with the grains produced more total solid content of the drinks than blade design with lesser contact with the grains. Thus, there was significant $(p \leq 0.05)$ increase between drink consistency produced from the speed of $1000 \mathrm{rpm}$ and that produced from $1400 \mathrm{rpm}$. Also, a significant $(\mathrm{p} \leq$ 0.05 ) decrease was observed between drink consistency produced from 3-blade assembly and 5-blade assembly.

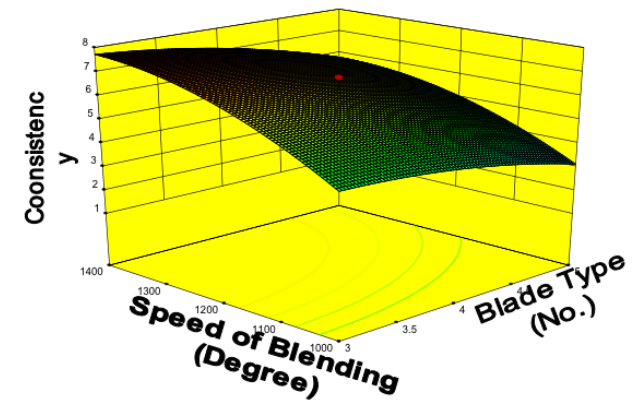

(a) Response Surface

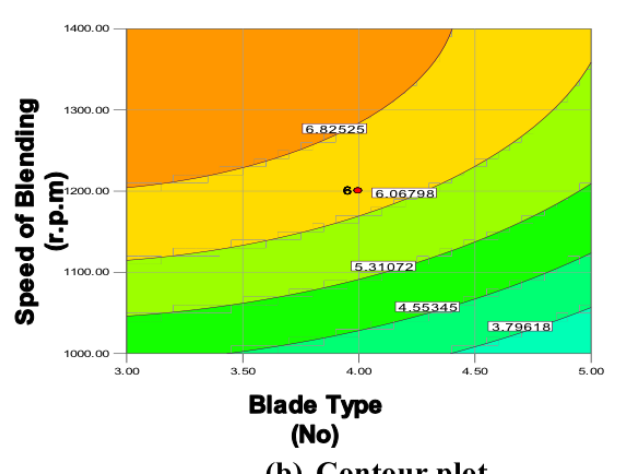

(b) Contour plot

Figure 2. Response surface (a) and contour plot (b) for response surface of milk consistency 


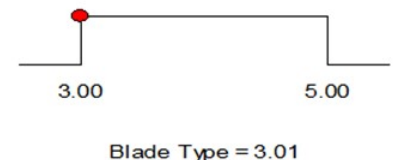

Blade Type $=3.01$

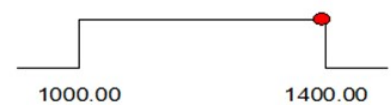

Speed $=1395.68$

Desirability $=0.999$

Figure 3. Ramp for Optimization of the machine performance parameters with the goal of maximising the consistency

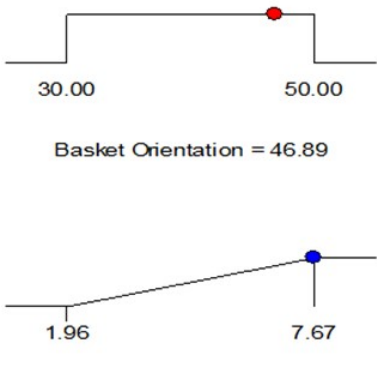

Mlk Consistency $=7.67953$
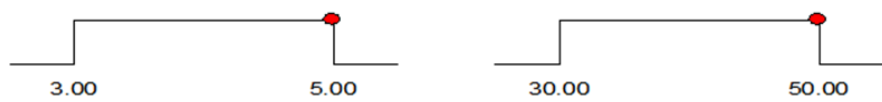

Blade Type $=5.00$

Basket Orientation $=50.00$
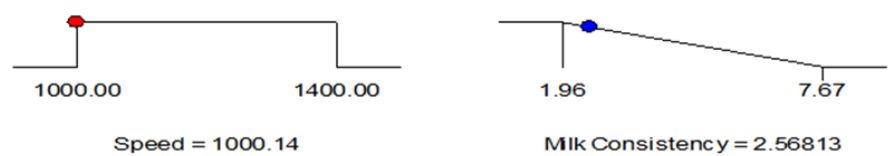

Desirability $=0.896$

Figure 4. Ramp for Optimization of the machine performance parameters with the goal of minimising the consistency

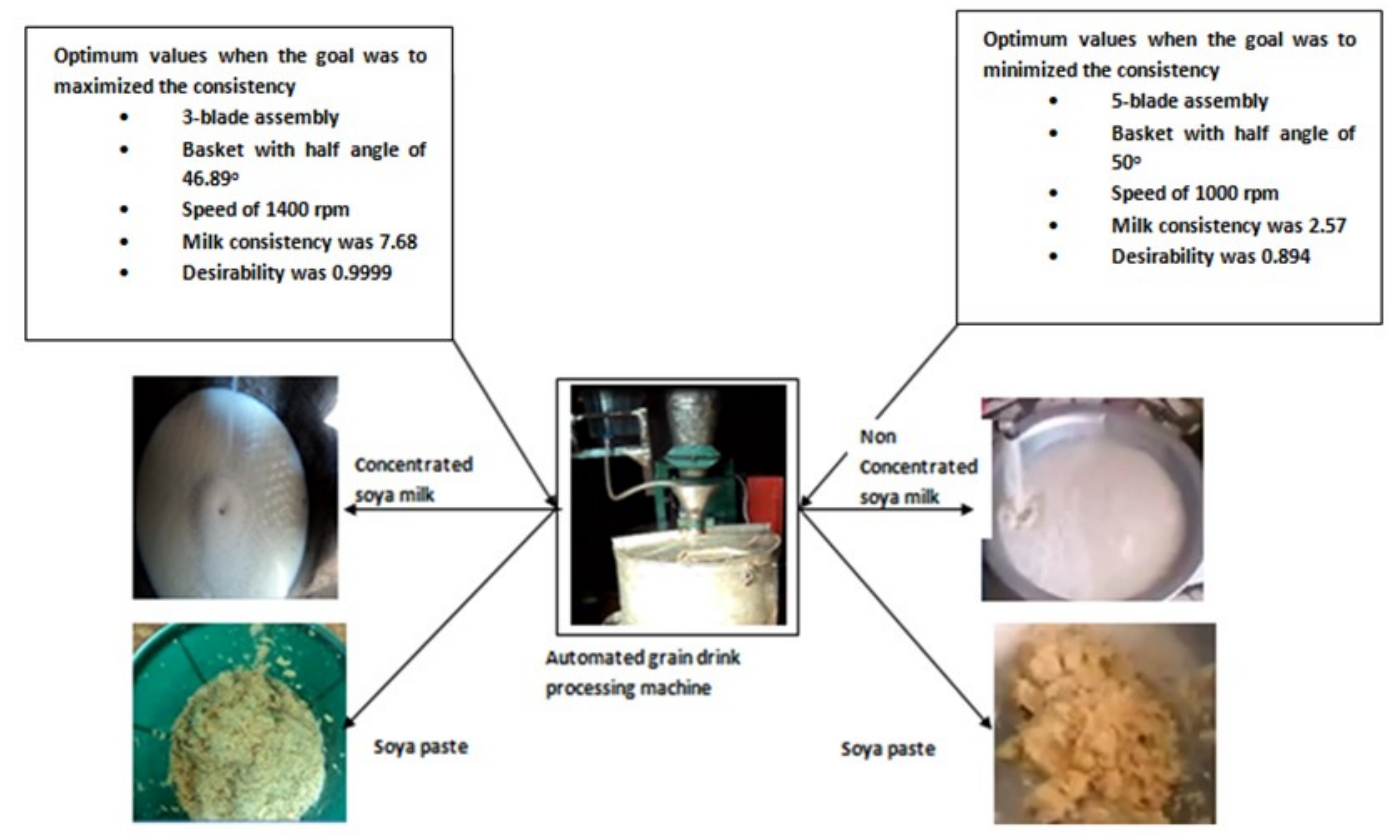

Figure 5. The optimum machine performance parameters with goals of minimizing and maximizing the soya milk consistency

\subsection{Effects of basket orientation on milk consistency}

From the analysis of variance (ANOVA) conducted basket orientation was observed to have no significant ( $\mathrm{P}$ $\leq 0.05$ ) effect on the milk consistency. There was no significant $(\mathrm{P} \leq 0.05)$ difference between the basket orientations with a half angle of $30^{\circ}$ and that of $50^{\circ}$.

\subsection{Optimisation of the machine functional parameters}

The ramp for the optimization is shown in Figures 3 and 4 . When the goal of the optimization is to maximise the consistency the optimum values of 3-blade assembly, basket with half angle $46.89^{\circ}$ and speed of $1400 \mathrm{rpm}$ were obtained for consistency of 7.68 with a desirability of 0.999. But when the goal is to minimize the consistency the optimum values of 5-blade assembly, basket with half angle $50^{\circ}$ and speed of $1000 \mathrm{rpm}$ were obtained, while the milk consistency and desirability were 2.59 and 0.86 respectively, as shown Figures 4 and 5.

\section{Conclusion}

The effects of mechanical parameters of an automated grain drinks processing machine on drink consistency are studied and major conclusions were as follows: the milk consistency increase with an increase in speed of blending from $1000 \mathrm{rpm}$ to $1400 \mathrm{rpm}$ and also with a decrease in blade type (number) from 5-blade assembly to 3-blade assembly. The basket orientation has no significant effect on drink consistency. Optimum values of 3-blades assembly, basket with half angle of $46.89^{\circ}$ and speed of $1400 \mathrm{rpm}$ were obtained for consistency of 7.68 with a desirability of 0.999 when the goal was to maximize the consistency (produced soya milk). On the other hand, when the goal was to minimize the consistency (produced soya beverage) the optimum values of 5-blades assembly, basket with half angle of $50^{\circ}$ and speed of $1000 \mathrm{rpm}$ was obtained for consistency of 2.57 with a desirability of 0.894 . Therefore, the blade type and speed of rotation were the most influential variables affecting the drink consistency. The result of this study provides standard input machine variables 
capable of yielding soya milk with various consistencies to meet the consumer's desire.

\section{Acknowledgement}

The authors would like to thank Dr. Adeshina Fadebiyi (Kwara State University Malete, Nigeria) and Dr. I. O. Olarinoye (Federal University of Technology Minna, Nigeria) for their contribution to the success of this research work and also the Tertiary Education Trust Fund (TetFUND), Nigeria for sponsoring one of the authors (Dr. Gana, Ibrahim Mohammed) to this conference.

\section{References}

Aminat, O., Adelekan, A.E.A., Ngozi, U.A., Yetunde, O.A. and Abidemi, S.D. (2013). Nutritional, microbiological and sensory characteristics of malted soy-kunu zaki: an improved traditional beverage. Advance in Microbiology, 3(4), 389-397. https:// doi.org/10.4236/aim.2013.34053

Anuonye, J.C. (2006). Effect of extrusion process variables on physioco-chemical, sensory, microbial and storage properties of products from acha (Digitariaexilis) and soybean (Glycine max (L) Merill) flour blends". Makurdi, Nigeria: University of Agriculture, $\mathrm{PhD}$ Thesis.

Aworanti, O.A., Agarry A.O. and Ajani, A.O. (2017). Statistical Optimization of process variables for biodiesel production from waste cooking oil using heterogeneous base catalyst. British Biotechnology Journal, 3(2), 116-132. https://doi.org/10.9734/ BBJ/2013/1381

Gaffa, T.I., Jideani, I.A. and Nkama I. (2003). Traditional production, consumption and storage of kunu - a non-alcoholic cereal beverage. Journal of Plant Food for Human Nutrition, 57(1), 73 - 81.

Gana, I.M. (2011). Development and performance evaluation of grain drinks processing machine. Nigeria: Federal University of Technology Minna, MSc Thesis.

Gana, I.M. (2016). Development and optimisation of functional parameters of an automated grain drinks processing machine. Nigeria: Federal University of Technology Minna, PhD Thesis.

Gana, I.M., Agidi, G., Idah, P.A. and Anuonye, J.C. (2017). Development and testing of an automated grain drinks processing machine. Journal of Food and Bioproducts Processing, 104, 19-31. https:// doi.org/10.1016/j.fbp.2017.04.002

Gbabo, A., Gana, I.M. and Solomon, M.D. (2012). Effect of blending speed on efficiency and consistency of a grain drinks processing machine. International
Journal of Agronomy and Agricultural Research, 2 (4), 1-6.

Jayesh, T. (2013). V-Blender, Lamar stone cypher 76. Retrieved from: http/www/brigthub.com/./aspr.

Maran, P. and Manikanda, S. (2012). Response surface modeling and optimization of process parameters for aqueous extraction of pigments from pea fruit. Dyes and Pigment, 95(3), 465-472. https:// doi.org/10.1016/j.dyepig.2012.06.007

Odu, N.N., Egbo, N.N. and Okonko, I.O. (2012). Assessment of the effect of different preservatives on the shell-life of soymilk stored at different temperatures. Researcher, 4(6), 62-69.

Onuorah, C.E., Adejare, A.O. and Uhiara, N.S. (2007). Comparative physico - chemical evaluation of soymilk and soya cake produced by three different methods. Journal of Nigerian Food, 25(2), 28-38

Salam, K.K., Arinkoola, A.O., Oke, E.O. and Adeleye, J.O. (2014). Optimization of operating parameters using response surface methodology for paraffinwax deposition in pipeline. Petroleum and Coal, 56 (1), 19-28

Shashikant., Roy, A.K. and Kumar, K. (2014). Effect and optimisation of various machine process parameters on the surface roughness in EDM for an EN19 material using response surface methodology. Proceeding of International Conference on Advance in Manufacturing and Materials Engineering AMME 2014. Procedia Materials Science, 5, 1702 - 1709

Soya Foods Association of America (SFAA). (1996). Voluntary standard for the composition and Labelling of soya milk in the United State. United States of America: The Soyfoods Association of America. Retrieved from: http://www.soyfoods.org/ wp-content/uploads/2006/11/smstandards.pdf

Terhaag, M.M., Almeidia, M.B., and Benassi, M.D.T. (2013). Soymilk plain beverages: correlation between acceptability and physical and chemical characteristics. Food Science and Technology (Campinas), 33(2). https://doi.org/10.1590/S010120612013005000052

Xin, L. and Saka, S. (2008). Optimization of Japanese beech hydrolysis treated with batch hot compressed water by response surface methodology. International Journal of Agricultural Biological and Engineering, 1(2), 239-245. 